\title{
NEPALESE PEOPLE'S KNOWLEDGE ABOUT TUBERCULOSIS
}

\author{
Bhatt $C^{1,2}$, Bhatt $A B^{1}$, Shrestha $B^{3}$ \\ ${ }^{1}$ Hemwati Nandan Bahuguna Garhwal University Srinagar Garhwal, India \\ ${ }^{2}$ Kathmandu Medical College, Sinamangal Kathmandu Nepal \\ ${ }^{3}$ German Nepal Tuberculosis Project, Kathmandu, Nepal
}

\begin{abstract}
Introduction : Tuberculosis (TB) is a major cause of illness and death worldwide, especially in Asia and Africa.

Objective: Objective of this study was to determine Nepalese people's knowledge about tuberculosis.

Methods : The diagnosed cases of tuberculosis was randomly selected, structured questionnaires were used to collect patient knowledge about tuberculosis.

Results : This prospective study included 300 diagnosed cases of pulmonary tuberculosis who were attending the DOTS programme of Nepal. Tuberculosis was most commonly found in economically active age group (21-50 years old). The incidence of tuberculosis was found higher in male than female. Regarding the common part of the body affected by TB bacilli $58 \%$ correctly said that it is the Lungs. About the mode of transmission of tuberculosis 50\% knew that it is transmitted by droplet infections. More then two third of the respondents had knowledge about the clinical symptoms of tuberculosis, among them chronic cough $(82 \%)$, evening rise of temperature $(72 \%)$ and blood in the sputum $(72 \%)$ were the major symptoms described. Only $16.6 \%$ of the respondents knew that Tuberculosis is an common opportunistic infection in people infected with HIVIAIDS. 53.3\% patients responded correctly that body secretion like sputum contains Tubercle Bacilli and regarding disposal of sputum and other body fluids $30 \%$ said that incineration is the proper way of disposal. On prevention of spread of tuberculosis $31.6 \%$ said that TB patients should use mask.

Conclusion : The study found that majority of the patients had satisfactory knowledge about the signs and symptoms of Tuberculosis but their knowledge about causative agent for Tuberculosis, disposal method for sputum and body fluid and preventive method for tuberculosis was still low. It is recommended that National tuberculosis control authority should design health education programme focusing on causative agents, disposal of sputum and body fluids and prevention of Tuberculosis. The awareness campaign should be targeted to patients, family members, community and health care providers and should be disseminated through the media that will reach the general Public. Such awareness campaign will increase the patient's general awareness about the disease and will help to reduce transmission of disease, prevent drug resistant cases and improve the efficacy of DOTS programme.
\end{abstract}

Keywords : HIVIAIDS, TB, Mycobacterium tuberculosis

\section{Correspondence to}

Chandra Prakash Bhatt

Asst. Professor

Dept. of Microbiology , Kathmandu Medical College

Sinamangal, Kathmandu

Health \& Environment Research Center.

E-mail drcpbhatt@yahoo.com, drcpbhatt@gmail.com

\section{INTRODUCTION}

Tuberculosis (TB) is a major cause of illness and death worldwide, especially in Asia and Africa. According to the World Health Organization (WHO), one third of the world's population has been exposed to the tuberculosis pathogen. ${ }^{1}$ By the end of 2007, 202 of 212 countries and territories had reported case notifications for 2006 and/or treatment 
outcomes for patients registered in 2005. These countries include $99.6 \%$ of the world's population. Surveillance and survey data has estimated that 9.2 million new cases of TB occurred in 2006 (139 per 100, 000), including 4.1 million (62 per 100000 ) new smear-positive cases. These numbers also includes TB in HIV-positive people. In terms of incidence, among the top five countries, India ranks first followed by China, Indonesia, South Africa and Nigeria. In 2006, Asia (South-East Asia and Western Pacific regions) accounted for $55 \%$ of global cases Africa $31 \%$ and other three regions accounted for remaining fraction of cases. ${ }^{2}$

Among the 9.2 million new cases of TB in 2006, it is estimated that around 709000 (7.7\%) were HIV-positive. This estimation is based on the global estimates of HIV prevalence among the general population (all ages) published by the Joint United Nations Programme on HIVI AIDS (UNAIDS) and WHO in December 2007. ${ }^{3}$ Tuberculosis is also the world's greatest infectious killer of women of reproductive age and the leading cause of death among people with HIVIAIDS. ${ }^{4}$

The rise in HIV infections and the neglect of TB control programs have enabled a resurgence of tuberculosis. ${ }^{5}$ The emergence of drug-resistant strains has also contributed to this new epidemic. From 2000 to 2004 it is estimated that $20 \%$ of TB cases are resistant to standard treatments and $2 \%$ resistant to second-line drugs. ${ }^{6}$ The incidence of TB varies with age. In Africa, TB primarily affects adolescents and young adults. ${ }^{7}$ However, in countries where TB has gone from high to low incidence, such as the United States, TB is mainly a disease of older people, or of the immunocompromised. ${ }^{8,9}$

There are a number of known factors that make people more susceptible to TB infection: HIV infection is one of the most important factor for susceptibility to TB infection as in Sub-Sahara African countries where the incidence of HIV is high. ${ }^{10,11}$ Smoking more than 20 cigarettes a day is said to increases the risk of TB by two to four times. ${ }^{12,13}$ Diabetes mellitus is also an important risk factor that is growing in importance in developing countries. ${ }^{14}$ Other disease states that increase the risk of developing tuberculosis are Hodgkin lymphoma, end-stage renal disease, chronic lung disease, malnutrition, and alcoholism. ${ }^{8}$

Tuberculosis (TB) still remains one of the major Public Health problems in Nepal. About $45 \%$ population is infected with $\mathrm{TB}$, of which $60 \%$ are adult. Every year, 40,000 people develop active TB, of whom 20,000 have infectious type of pulmonary TB. Although introduction of DOTS has already reduced the numbers of deaths, however 5,000 to 7,000 people still continue to die each year. ${ }^{15}$

The burden of TB has significantly increased because of increased transmission due to Population migration, armed conflict and refugee movement Tuberculosis is transmitted mainly by droplet infection and droplet nuclei generated by sputum positive patients with pulmonary tuberculosis. To transmit infection, the particles must be fresh enough to carry a viable organism. Coughing generates the largest number of droplets of all sizes. The frequency and vigour of cough and the ventilation of the environment influence transmission of infection. Patients with extra-pulmonary tuberculosis or smear negative tuberculosis constitute a minimal hazard for transmission of infection. Tuberculosis is a social disease with medical aspects. The social factors include many non-medical factors such as poor quality of life, poor housing, and overcrowding, population explosion, under-nutrition, lack of education, large families, early marriages, lack of awareness of causes of illness, etc. ${ }^{16}$

\section{OBJECTIVE}

Objective of this study was to determine Nepalese people's knowledge about tuberculosis.

\section{MATERIALS AND METHODS}

The present prospective study was carried out among tuberculosis patients attending Directly Observed Treatment Short Course (DOTS) Programme in Kathmandu Medical College, Sinamangal and German Nepal Tuberculosis Project Kathmandu, Nepal, during the period from January 2006 to December 2007. A structured questionnaire prepared in English and translated into Nepali language was the tool for data collection. The research objective and methods were explained to the patients, and verbal consent was obtained from them before data collection. Random Sampling method was used to select the target population for the survey. Open ended self administered questionnaires based on the knowledge about Tuberculosis were given to the survey population, literate group were asked to fill up the questionnaire and illiterate group were interviewed by trained interviewer.

The questionnaire consisted of two sections: Section one had details about the patient's background characteristics (age, sex,). Section two consisted of details about knowledge on Tuberculosis like parts of the body affected by TB bacilli, mode of transmission, clinical symptoms, 
relationship of HIV and TB, body secretion where tubercle bacilli are found, and proper disposal of sputum and other body fluids. The questionnaire also contains knowledge of the participant on preventive method of tuberculosis transmission.

Data was analyzed by EPI-Info version 3.3.2, document version 8.08 updated Sept 2005 and presented by means of tables and diagrams.

\section{RESULTS}

The majority $(73 \%)$ of the respondents were in the age group of $21-50$ years, with males being more $(64 \%)$ then

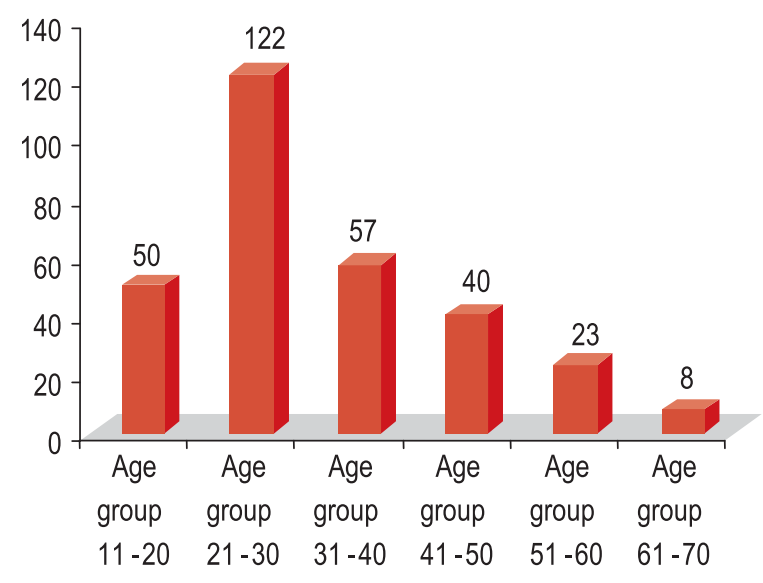

Figure 1: Age wise distribution of patients

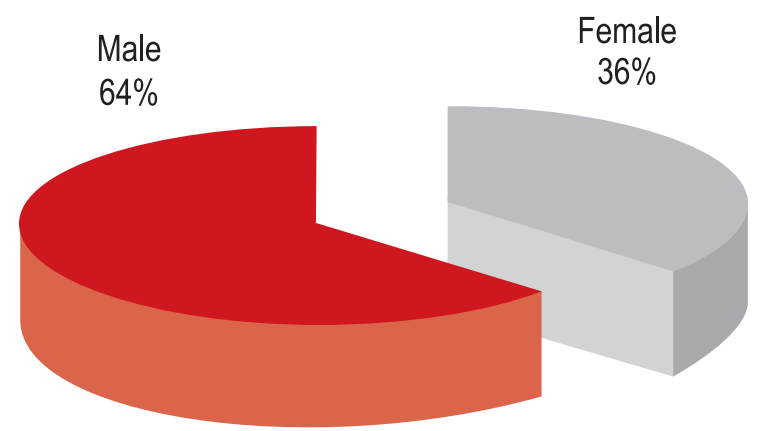

Figure 2: Gender wise distribution of patients

females (36\%). Age and sex wise distribution of patients are shown in figure 1 and 2 respectively.

Knowledge on the parts of the body affected by TB bacilli, $58 \%$ of the respondents had answered correctly by mentioning lungs as the main part affected (Table 1). Regarding the transmission of tuberculosis $50 \%$ of the respondents knew correctly that $\mathrm{TB}$ is transmitted through droplet infection (Table 2). Knowledge on the clinical symptoms of tuberculosis, majority (82\%) answered chronic cough, followed by fever (74\%), blood in sputum (72\%) loss of weight (50\%) and loss of appetite $(50 \%)$. This shows that two third of the respondent knew the common symptoms of Tuberculosis (Table 3).

On the knowledge about association of TB with HIVIAIDS only $16.6 \%$ knew that TB is the commonest opportunistic infection in people infected with HIVIAIDS (Table 4). More than two third of the respondents knew correctly that body secretion which contains TB bacilli is sputum (Table 5 ).

Knowledge on the suitable method for disposal of body fluids and sputum containing TB bacilli, only 30\% knew the correctly that incineration was the suitable method of disposal (Table 6). On preventing the transmission of Tuberculosis $31.6 \%$ of the respondents felt that TB patients should use mask (Table 7).

\begin{tabular}{lll|}
\multicolumn{3}{c}{ Table 1: Parts of the body affected by TB bacilli } \\
\hline Parts of the body & Frequency & Percentage \\
\hline Lung & 174 & $58 \%$ \\
Chest & 30 & $10 \%$ \\
Lung and liver & 15 & $5 \%$ \\
Lung and chest & 14 & $4.6 \%$ \\
Lung and skin & 7 & $2.3 \%$ \\
Don't know & 60 & $20 \%$ \\
\hline
\end{tabular}

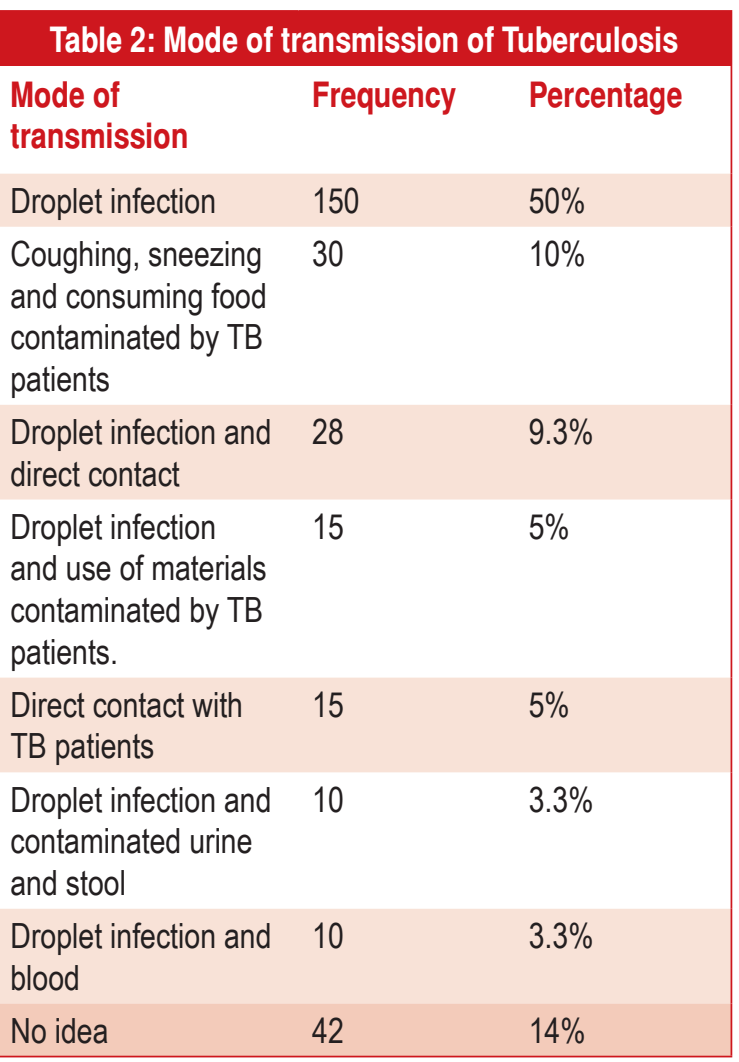




\begin{tabular}{|c|c|c|}
\hline $\begin{array}{l}\text { Clinical } \\
\text { symptoms }\end{array}$ & $\begin{array}{l}\text { Frequency } \\
(300) \text { for each } \\
\text { symptom }\end{array}$ & Percentage \\
\hline I. Chronic cough & 246 & $82 \%$ \\
\hline $\begin{array}{l}\text { II. Fever in the } \\
\text { evening }\end{array}$ & 222 & $74 \%$ \\
\hline III. Blood in sputum & 216 & $72 \%$ \\
\hline IV. Loss of weight & 150 & $50 \%$ \\
\hline V. Loss of appetite & 150 & $50 \%$ \\
\hline VI. Chest pain & 123 & $41 \%$ \\
\hline
\end{tabular}

\section{Table 4: HIV and its relation with Tuberculosis}

\begin{tabular}{lll}
\hline $\begin{array}{l}\text { HIV and its relation with } \\
\text { tuberculosis }\end{array}$ & Frequency & Percentage \\
$\begin{array}{l}\text { HIV is an un-curable } \\
\text { disease and TB is curable } \\
\text { disease }\end{array}$ & 55 & $18.3 \%$ \\
$\begin{array}{l}\text { TB is common } \\
\text { opportunistic infection } \\
\text { among HIV patients }\end{array}$ & 50 & $16.6 \%$ \\
$\begin{array}{l}\text { Mode of transmission } \\
\text { of HIV is unsafe sexual } \\
\text { contact and TB by droplet } \\
\text { infection, smoking and }\end{array}$ & 40 & $13.3 \%$ \\
alcohol drinking habit. & & \\
$\begin{array}{l}\text { No relation between TB } \\
\text { and HIV }\end{array}$ & 30 & $10 \%$ \\
$\begin{array}{l}\text { Don't know any relation } \\
\text { between TB and HIV }\end{array}$ & 45 & $15 \%$ \\
Don't know about HIV & 80 & $26.6 \%$ \\
\hline
\end{tabular}

\section{Table 5: Body secretion where Tubercle bacilli} are found

\begin{tabular}{|c|c|c|}
\hline $\begin{array}{l}\text { Body secretion where } \\
\text { tubercle bacilli are } \\
\text { found }\end{array}$ & Frequency & Percentage \\
\hline Sputum & 160 & $53.3 \%$ \\
\hline Sputum and saliva & 33 & $11 \%$ \\
\hline Sputum, saliva and urine & 21 & $7 \%$ \\
\hline Sputum, blood and saliva & 20 & $6.6 \%$ \\
\hline Sputum and stool & 15 & $5 \%$ \\
\hline $\begin{array}{l}\text { Sputum, blood, saliva and } \\
\text { urine }\end{array}$ & 6 & $2 \%$ \\
\hline $\begin{array}{l}\text { Sputum, saliva, blood, } \\
\text { urine and stool }\end{array}$ & 6 & $2 \%$ \\
\hline Urine and stool & 6 & $2 \%$ \\
\hline Don't know & 33 & $11 \%$ \\
\hline
\end{tabular}

Table 6: Disposable method of Sputum and other Body fluids

\begin{tabular}{|c|c|c|}
\hline $\begin{array}{l}\text { Disposable } \\
\text { method }\end{array}$ & Frequency & Percentage \\
\hline Digging & 105 & $35 \%$ \\
\hline $\begin{array}{l}\text { Incineration and } \\
\text { digging of sputum }\end{array}$ & 39 & $13 \%$ \\
\hline $\begin{array}{l}\text { Incineration, } \\
\text { digging and use of } \\
\text { disinfectant }\end{array}$ & 27 & $9 \%$ \\
\hline Incineration & 24 & $8 \%$ \\
\hline $\begin{array}{l}\text { Chemotherapy } \\
\text { reduce infectivity }\end{array}$ & 21 & $7 \%$ \\
\hline Don't know & 84 & $28 \%$ \\
\hline
\end{tabular}

\begin{tabular}{|lcc|}
\hline \multicolumn{3}{|c|}{ Table 7: Preventive method of Tuberculosis } \\
\multicolumn{1}{|c|}{ Transmission } \\
\hline $\begin{array}{l}\text { Preventive } \\
\text { method }\end{array}$ & Frequency & Percentage \\
$\begin{array}{l}\text { TB patients should } \\
\text { use mask }\end{array}$ & 95 & $31.6 \%$ \\
$\begin{array}{l}\text { Don't use TB } \\
\text { patient's utensils } \\
\text { and cloths }\end{array}$ & 65 & $21.6 \%$ \\
$\begin{array}{l}\text { Separate the TB } \\
\text { patients from } \\
\text { community }\end{array}$ & 54 & $18 \%$ \\
$\begin{array}{l}\text { TB patients should } \\
\text { use mask and } \\
\text { properly dispose } \\
\text { patient's sputum } \\
\text { and other materials }\end{array}$ & 21 & $7 \%$ \\
$\begin{array}{l}\text { Don't visit the TB } \\
\text { patients }\end{array}$ & 15 & $5 \%$ \\
$\begin{array}{l}\text { TB patient should } \\
\text { treat as early as } \\
\text { possible }\end{array}$ & 15 & $5 \%$ \\
Don't know & 35 & $11.6 \%$ \\
\hline
\end{tabular}

\section{DISCUSSION}

The finding of this study showed that majority $(73 \%)$ of the TB patients belong to the economically active young age group of 21-50 years, this finding is consistent with the earlier finding of Bam (2003). ${ }^{17}$ where $95 \%$ of TB patients were in the age group of $15-54$ years. This finding suggests that $\mathrm{TB}$ is common among the economically active group having direct impact to the family and the national economy. This finding also supports the global burden of TB in developing countries where $75 \%$ of cases are within 
the economically and most productive age group (15-54 years)..$^{15}$ This finding of the study also suggests that burden of TB will cause economic loss to the family and community in Nepal because it is found that an adult with TB, in the developing world loses on average 3-4 months of work time, $20 \%-30 \%$ of annual house hold income and 15 years income if patient dies causing staggering economic loss to the family and the community. ${ }^{18}$

More males (64\%) were found to be suffering from TB compared to females $(36 \%)$ this could be possible due to sampling bias where more males were included in the study then females, however this finding is consistent with earlier findings by Bam $(65 \%)$ in (2003). ${ }^{17}$ Low incidence of TB among females in this study could also be because of the low status accorded to women in Nepal where male domination still exists and women has limited decision making power, restricted mobility and poor access to basic and available health care. Women in Nepal may be more vulnerable to TB because of gender disparity that still exist giving women less opportunity for education, food and nutrition. On the other hand, the higher incidence of TB among man could be attributed to vulneralibity of men to TB because of their mobile life style and exposure to predisposing factors like smoking, alcohol, drug abuse.

Majority (58\%) of respondents knew correctly that common part of the body infected by TB is the lungs and $53.3 \%$ of the participants of the survey responded correctly that TB bacilli are excreted in the sputum. But only $30 \%$ of them were aware that incineration is the appropriate way of disposition of sputum and other body fluids. Above findings are important for developing prevention strategies for TB because TB disease primarily affects lungs causing pulmonary tuberculosis ${ }^{19,20}$ and patient excreting TB bacilli in the sputum are the principal sources of infection. ${ }^{23}$ People with prolonged, frequent, or intense contact are at particularly high risk of becoming infected, with an estimated $22 \%$ infection rate. A person with active but untreated tuberculosis can infect 10-15 other people per year. ${ }^{21}$

Knowledge on the transmission of tuberculosis showed that only $50 \%$ of patients knew that tuberculosis is infectious disease transmitted by droplet infection. Only $32 \%$ of respondent knew that use of mask by TB patient can prevent Tuberculosis. A similar study conduct by Joshi et al. $(2006)^{22}$ showed that out of 58 respondents 28 were of the view that to prevent the transmission of TB it is advised not to sleep in a common place and 32 said transmission could be prevented by covering their mouth while coughing. Above findings of this study suggests that more emphasis should be given on teaching patients on mode of transmission of TB bacilli and using mask to prevent transmission of TB, because use of face mask by TB patients decreases the risk of transmission of TB infection to others.

It had been found that majority of the respondents (82\%) were aware of tuberculosis symptoms such as coughing $(82 \%)$, fever in the evening $(74 \%)$ and blood in sputum $(72 \%)$. These findings are significant for future intervention in TB control because sociological studies carried out in India have shown that an overwhelming majority of patients of pulmonary tuberculosis have one or more of the symptoms referable to chest, such as persistent cough and fever, and many of them (over 60 per cent ) seek medical advice on their own initiative. The chest symptoms often develop early, that is before the disease has gone on to an advanced stage..$^{23}$

Knowledge of the surveyed population on the relationship of TB with HIV showed that only $16.6 \%$ of the respondents were aware that TB is common opportunistic infection among HIV patients. This finding suggests that the knowledge of the TB patient about TB and HIV co-infection is poor. Because the rate of progression to clinical TB disease is 10 to 30 times higher among individuals infected by both TB and HIV than among those infected only with TB. This is because people with HIV infection have suppressed immunity and hence chances of reactivation of dormant TB bacilli is many fold higher in them than among those without HIV. Moreover, due to low immunity, natural infection may rapidly lead to TB disease. Therefore, HIV infected persons are likely to get numerous opportunistic infections including TB. HIV is therefore considered the most important risk factor for TB in many countries. HIV is likely to worsen the TB situation in most countries with advanced HIV epidemic. Moreover, this may also contribute to an increase in drug resistance. The annual risk of developing TB in HIV infected individuals coinfected with MTB is $5-10 \%$. Lifetime risk of development of active TB among co infected people (latent MTB and HIV) is $60 \%$ and among latent MTB infected individuals is $10 \%$. TB is the most common causes of HIV related illness and death. HIV not only increases the number of TB cases, but also alters the clinical course of TB disease. ${ }^{24}$

\section{CONCLUSION AND RECOMMENDATIONS}

The finding of this study has found that respondents had adequate knowledge about the common signs and symptoms of Tuberculosis and more then 50\% knew about 
the common part of the body infected by TB bacilli. These are important findings because signs and symptoms are important for early diagnosis and treatment and reduce the spread of Tuberculosis in the community.

The surveyed population had less representation from the female gender so it is recommended that future studies may be carried out with equal representation from both sexes. On the mode of transmission only $50 \%$ knew correctly that it is transmitted by droplet infection, and few percentages of patients knew the other methods of transmission. It is recommended that emphasis should be given to improve the knowledge of the people on all the methods of TB transmission. Majority of the patients knew about the common clinical symptoms of TB like chronic cough (82\%), fever in the evening $(74 \%)$, blood in sputum $(72 \%)$, this finding suggests that awareness to the patient on clinical feature of TB has been good.

Knowledge on the association of TB and HIV was low with only $16.6 \%$ responding that there is association between TB and HIV. It was also found that $26 \%$ of the patients did not know about HIV. This finding suggests that HIV/TB collaborative activities should be strengthened in order to increase the knowledge of patients on TB/HIV association. It is also recommended that such interventions should be targeted towards TB patients as well as HIV positive patients.

On Patient's knowledge on body secretion containing TB bacilli $53.3 \%$ answered correctly that sputum contains TB bacilli. Since TB is transmitted from sputum positive patients it is important that more awareness should be given on this subject.

The finding of the study on the knowledge of patients on proper disposal of sputum, it was observed that there was no significant positive finding. This suggests that more awareness should be given to patients on proper disposal so that transmission could be reduced.

Knowledge on the prevention of TB transmission, it was observed that only $31.6 \%$ knew that TB patients should use mask, this may be because patients must be thinking of using a medical mask for prevention, so in future health education programs for patients it may be emphasized that covering of mouth while coughing and use of other forms of masks like handkerchief can also be used.

There were also important findings on the knowledge of patients on prevention where only $18 \%$ felt that TB patients should be separated from the community and $5 \%$ said not to visit TB patients. These findings suggest that patients had knowledge that TB patients should not be stigmatized.

Over all findings of the study suggests that health education and awareness program for TB patients should be strengthened and it should contain all aspect of the TB prevention. This study is done only in two centers so the findings and recommendations should not taken for the whole of Nepal. Further study is recommended to develop a general guideline for developing awareness campaign and health education for TB patients.

\section{ACKNOWLEDGEMENT}

The authors would like to thank Dr. D. S. Bam, Sectary, Ministry of Health, Government of Nepal and Exdirector of IUATLD and SAARC TB Centre. Dr. P. Malla, Director National Tuberculosis Centre, Mr. B Maharjan, Lab technologist, GENTUP, Nepal, Bijay Pandey (BDS Student) and all the staffs of Nepal Tuberculosis Control Programme (DOTS) and German Nepal Tuberculosis Project, Kalimati Kathmandu, Nepal, Kathamndu Medical College Kathamandu Nepal, HNB Garhwal University Srinagar Garhwal Uttranchal India for their cooperation and support during this study.

\section{REFERENCES}

1. National Institute of Allergy and Infectious Diseases (NIAID). [2] 26 October 2005. Retrieved on 3 October 2006.

2. World Health Organization (WHO). Tuberculosis control, surveillance, planning, financing. World Health Organization, 2008.

3. AIDS epidemic update. 2007. Geneva, Joint United Nations Programme on HIVIAIDS and World Health Organization, 2007.

4. Stop TB Partnership. London tuberculosis rates now at Third World proportions. PR Newswire Europe Ltd. 4 December 2002. Retrieved on 3 October 2006

5. lademarco MF and Castro KG. Epidemiology of tuberculosis. Seminars in respiratory infections. 2003; 18 (4): 225-40

6. Emergence of Mycobacterium tuberculosis with extensive resistance to second-line drugs-worldwide, 2000-2004. MMWR Morb Mortal Wkly Re; 2006: 55 (11): 301-5.

7. World Health Organization (WHO). 2006. Global Tuberculosis Control Report, 2006 - Annex 1 Profiles of high-burden countries. (PDF). Retrieved on 13 October 2006. 
8. Kumar Vinay Abbas, Abul K, Fausto Nelson, and Mitchell Richard N. Robbins Basic Pathology (8th ed.) 2007. Saunders Elsevier. pp. 516-522

9. Centers for Disease Control and Prevention (CDC). 2005. Surveillance Slide Set. (September 12, 2006) Retrieved on 13 October 2006.

10. World Health Organization (WHO). 2006. Global tuberculosis control - surveillance, planning, financing WHO Report. Retrieved on 13 October 2006

11. Chaisson RE and Martinson NA. Tuberculosis in Africacombating an HIV-driven crisis. N Engl J Med. 2008: 358 (11): 1089-1092.

12. Davies PDO, Yew WW and Ganguly D. Smoking and tuberculosis: the epidemiological association and pathogenesis. Trans R Soc Trop Med Hyg. 2006: 100: 291-8.

13. Jha P, Jacob B and Gajalakshmi V. Anationally representative case-control study of smoking and death in India. N Engl J Med; 2008: 358 (11): 1137-1147.

14. Restrepo BI. 2007. Convergence of the tuberculosis and diabetes epidemics: renewal of old acquaintances . Clin Infect Dis. 2007; 45: 436-8.

15. SAARC Tuberculosis and HIVIAIDS centre. Tuberculosis in the SAARC region, an update. SAARC Tuberculosis and HIVIAIDS centre, Kathmandu Nepal.2007.

16. Park. K. Park's textbook of preventive and social medicine. Nineteenth edition Publisher M/s Banarsidas Bhanot 1167, Prem Nagar, Jabalpur, 482001 India 2007 p 149-165.
17. Bam TS. Factors affecting patients' compliance with directly observed treatment short course in Kathamndu urban areas, Nepal. Thesis submitted to master of primary health care management faculty of graduate studies Mahidol University Thailand.2003.

18. SAARC TB centre. Gender differences among TB patients in NTPs within SAARC member countries. SAARC TB Centre, Kathmandu Nepal. January 2002.

19. Sudre $P$, ten Dam $G$ and Kochi $A$. Tuberculosis: a global overview of the situation today. Bull WHO. 1992; 70: 14959.

20. Parrish NM, Dick JD and Bishai WR. 1998. Mechanism of latency in Mycobacterium tuberculosis trends. Microbiol; 1998: 6: 107-12.

21. Rouillon A, Perdrizet S and Parrot R. 1976. Transmission of tubercle bacilli: the effect of chemotherapy. Tubercle; 1997: 57: $275-99$

22. Joshi RS, Maharjan M and Zimmerman MD. Tuberculosis awareness among TB patients visiting in DOTS clinic in Patna Hospital. SAARC Journal of Tuberculosis, Lung Disease and HIVIAIDS; 2006 (1): 20-25

23. Editorial. April. Ind J Tuberculosis; 1985: 32: 169.

24. SAARC guidelines for partnership with Pharmacists in prevention and control of Tuberculosis and HIV/ AIDS. SAARC Tuberculosis and HIVIAIDS Centre, Thimi, Bhaktapur, Kathmandu Nepal.2006. 